\title{
Masonería y espacio público: El debate en torno a la "escuela atea" en Chile 1872
}

\author{
Freemasonry and Public Space: \\ The "Atheist School" debate in Chile 1872
}

\author{
Ivonne Cortés \\ Universidad Autónoma de Chile \\ ivocortes@live.cl
}

Recepción: 26 de marzo de 2018/Aceptación: 22 de abril de 2018.

doi: https://doi.org/10.15517/rehmlac.v10i1.32839

Palabras clave

Esfera pública; masonería chilena; educación; laicismo; Iglesia católica.

Keywords

Public Sphere; Chilean Freemasonry; Education; Secularism; Catholic Church.

Resumen

En Chile a mediados del siglo XIX, el tema de la educación fue adquiriendo gran importancia en el debate público. Desde aquí, las autoridades problematizaban acerca del mejor modelo educativo para el desarrollo de la República y la consecución del progreso. En este contexto, se produjo en Valparaíso, un enfrentamiento entre dos modelos de modernidad, que por ese entonces disputaban su legitimidad en la naciente esfera pública. Por una parte, la masonería impulsó un desafiante proyecto educativo laico al fundar la escuela "Blas Cuevas". La Iglesia católica y sus defensores por su parte, en defensa de un proyecto más tradicionalista, se opusieron fervientemente a la iniciativa calificándola de "atea" e iniciando una ofensiva comunicacional en su contra. Nuestro trabajo busca analizar el debate entre ambos actores, dando cuenta de sus argumentos, estrategias y legitimación como actor dentro de la esfera pública.

Abstract

In Chile in the mid-nineteenth century, the issue of education was gaining importance in the public sphere. From then on, the authorities hypothesized on the educational model that would best promote the development and advancement of the Republic. In that context, in Valparaiso there was a clash between different models of modernity, disputing the legitimacy of the nascent public sphere. On one side, Freemasonry spearheaded a challenging secular educational project by founding the school, "Blas Cuevas". In defense of a more traditional project, the Catholic Church and its supporters were strongly opposed to the initiative, calling it "atheist" and initiating a communication offensive against them. Our work seeks to analyze the debate developed by these two actors, their arguments, strategies, and legitimation on the public sphere.

\section{Introducción}

El siguiente trabajo se centra en la polémica producida en la prensa a propósito de la fundación en 1872 de la Escuela Blas Cuevas, primera institución de carácter laico fundada por la masonería. 
Para el análisis del debate, se utilizaron las cartas que fueron publicadas en los periódicos La Patria y El Mercurio de Valparaíso, la Revista Católica, El Independiente, y El Ferrocarril de la ciudad de Santiago entre los meses de noviembre de 1872 a enero de 1873.

Con ese material hemos reconstruido algunos aspectos de la polémica, los cuales dan cuenta, por una parte, de la resistencia de los sectores conservadores frente a la irrupción de la modernidad, en este caso del protestantismo y por otro lado la masonería, como también, de las estrategias que nuevos actores fueron desplegando para ganar protagonismo en la naciente esfera pública.

Nuestra hipótesis al respecto es que la masonería se vio beneficiada del debate, ya que a través de este logró darse a conocer en la sociedad chilena al mismo tiempo que le permitió alinearse políticamente con aquellos sectores del liberalismo que en ese mismo momento se encontraba en pugna con la Iglesia católica.

Nuestro artículo está compuesto de dos partes, en la primera, situamos el problema en torno al ideal de educación esgrimido por los sectores liberales y la utilización del espacio público para su difusión; en la segunda parte, entramos directamente al debate en torno a la Escuela Blas Cuevas dando cuenta cómo este se insertó dentro de un debate mayor como lo fue la pugna entre tradición y modernidad.

\section{La educación como motor del progreso}

A mediados del siglo XIX, la inestabilidad de los primeros años de independencia en Chile parecía haber quedado atrás, una vez instaurado cierto orden político y social, la elite dirigente se aventuraba a la consolidación de la República y a la consecución de lo que para ellos era el progreso y la civilización.

En el periodo, los intelectuales que se encaminaron en la construcción de la nación moderna, confiaban en que el tiempo conduciría al progreso del país, concebían que el uso de la razón y la práctica de las ideas ilustradas tendría como resultado una mejora material y moral de la República, lo que indudablemente derivaría en el bienestar de la humanidad ${ }^{1}$. Uno de los caminos para estos fines fue la educación, presentada como liberadora del atraso, por lo cual se propuso estimularla con toda energía ya que se pensaba que a través de esta se terminaría con la "barbarie", A través de la educación se formaría un hombre

\footnotetext{
${ }^{1}$ José Luis Romero, Latinoamérica. Las ciudades y las ideas (Buenos Aires: Siglo XXI, 2001).

2 Jorge Pinto Rodríguez. "Proyectos de la elite chilena del siglo XIX", ALPHA 27 (2008): 124. Para una mayor profundización del tema ver: Alfredo Jocelyn-Holt, "Liberalismo y Modernidad. Ideología y Simbolismo en el Chile Decimonónico: Un Marco Teórico", en La Revolución Francesa y Chile, eds. Ricardo Krebs y Cristián Gazmuri (Santiago: Ed. Universitaria, 1990); Ana María Stuven, La Seducción de un orden: las élites y la construcción de Chile en las polémicas culturales y políticas del siglo XIX (Santiago: Ediciones Universidad Católica de Chile, 2000); y Simon Collier. Chile: la construcción de una república 1830-1865: política e ideas (Santiago: Ediciones Universidad Católica de Chile, 2005).
} 
nuevo, ciudadano de la República. Si la virtud era el principal valor individual y colectivo, la educación era el medio idóneo para formarla.

En este sentido, el Estado chileno inició una intensa política de escolarización ${ }^{3}$, como una medida de reforma social, con la finalidad de educar a la población en los principios de la modernidad. A partir de la escuela se buscaba formar a los ciudadanos en los valores de la patria, ya que el objetivo era cortar con los lazos comunitarios tradicionales hispanos y forjar unos nuevos basados en la racionalidad a partir de la cultura escrita. Se buscaba construir una sociedad de individuos que se comportasen racionalmente, tanto en el espacio privado de la familia como en el espacio público, identificado este último con la ciudadanía y la mantención del orden social.

La escuela sería, entonces, la institución a partir de la cual los individuos adquirirían los hábitos y conductas necesarias para legitimar el orden en la nación a partir de la racionalización y moralización de las conductas, lo cual significaba, erradicar las costumbres tradicionales por unas fundadas en una nueva moralidad ${ }^{4}$.

Para la elite ilustrada, la mayor parte de la población no estaba a la altura del orden republicano, por ende, el impulso a la educación trataba de inventar al ciudadano difundiendo en la base de la sociedad los principios y valores de la Ilustración y promoviendo prácticas que contribuyeran a formarlo. Esto se tradujo en la creación y promoción de instituciones educativas y civiles, tales como asociaciones y clubes, ya que estos eran considerados ámbitos ideales para el desarrollo de la ciudadanía moderna ${ }^{5}$.

Según Ana María Stuven, la educación a lo largo del siglo XIX era el eslabón que unía al hombre pre republicano, ignorante e incivilizado con el progreso, por tanto era una tarea prioritaria del Estado, ya que ésta permitiría que las incertidumbres propias del establecimiento de un nuevo orden no se tuvieran que expresar con la desestabilización social $^{6}$. Por tanto, la educación funcionaba como un cohesionador entre el Estado y la nación, el gobierno y los gobernados ${ }^{7}$.

De esta forma el nuevo orden social se iba articulando en la medida que también lo hacía la sociabilidad chilena ${ }^{8}$. Así, la esfera pública se ensanchaba como consecuencia de la

\footnotetext{
${ }^{3}$ El tema es tratado ampliamente en Sol Serrano, Macarena Ponce de León y Francisca Rengifo, Historia de la Educación en Chile (1810-2010), Tomo I. Aprender a leer y escribir (1810-1880) (Santiago: Editorial Taurus, 2013).

${ }^{4}$ Serrano, "La escuela chilena y la definición de lo público", en Los espacios públicos en Iberoamérica. Ambigüedades y problemas. Siglos XVIII-XIX, eds. François-Xavier Guerra y Annick Lempérière (Ciudad de México: Fondo de Cultura Económica, 1998), 340-362.

${ }^{5}$ Hilda Sabato, lo explica de forma muy detallada para el caso argentino en: "La esfera pública en Iberoamérica. Reflexiones sobre los usos de una categoría", en Peter Sociedad civil en América Latina: representación de intereses y gobernabilidad, eds. Karl Kohut Hengstenberg y Gunther Maihold (Caracas: Friedrich Ebert Stiftung/Nueva Sociedad, 1999), 47-59.

${ }^{6}$ Stuven, La Seducción de un Orden, 66.

${ }^{7}$ Serrano, Universidad y Nación. Chile en el siglo XIX (Santiago: Universitaria, impresión de 1994), 42.

8 Apropósito ver Gazmuri. El "48" chileno: igualitarios, reformistas radicales, masones y bomberos (Santiago: Universitaria, 1999).
} 
expansión del tejido asociativo y el universo de la prensa. Esta última fue una de las conductoras del debate en el espacio público, convirtiéndose en el espacio privilegiado para la polémica 9 .

\section{Esfera pública y el debate entre el liberalismo y la Iglesia católica}

Durante este periodo, el liberalismo va marcando su hegemonía en los ámbitos políticos, culturales y sociales. A partir de la década de 1870 con el ascenso de los gobiernos liberales, se fueron sucediendo reformas constitucionales que apuntaban a la ampliación formal y legal de las libertades públicas y fue el ámbito de la prensa ${ }^{10}$ uno de los primeros en donde se hizo sentir el proyecto de modernización liberal. El periodismo tuvo un notable desarrollo en esta década, momento en el cual comienza a configurarse la prensa liberal moderna, la cual tiene como principales rasgos su carácter informativo más que doctrinario y propulsor del debate en la esfera pública. En este periodo la publicación de periódicos tuvo un crecimiento explosivo, según Bernardo Subercaseaux, en 1840 existían 5 diarios y en 1880 más de cien ${ }^{11}$.

Uno de los principales temas que suscitó profundo debate en la prensa fue el conflicto entre la Iglesia y Estado a propósito de la libertad de enseñanza, de hecho este elemento abrió el enfrentamiento entre la elite liberal y conservadora del país. Según Sol Serrano, el modo de concebir la escuela en el periodo detonó entre otras cosas, la discusión de la secularización del Estado y la definición de lo público como un ámbito distinto del religioso. El debate tenía su origen en el principio de libertad de conciencia, ya que los liberales abogaban que las personas que no pertenecieran a la religión católica pudieran practicar su culto y su enseñanza libremente, mientras los conservadores ultramontanos, se oponían a la tolerancia religiosa y dejaban como único espacio de disidencia el doméstico.

Como una solución parcial al debate, la ley estableció en 1865 que quienes no eran católicos podrían realizar su culto dentro de propiedades particulares y se les autorizaba a sostener escuelas privadas. Según la autora, el debate a propósito de la escuela y la ley de 1865, fue el primer paso legislativo hacia la secularización del Estado, el cual culminó con

\footnotetext{
${ }^{9}$ Stuven. La Seducción de un Orden, 66.

${ }^{10}$ Para el desarrollo de la prensa en el periodo. Carlos Ossandón y Eduardo Santa Cruz, Entre las Alas y el Plomo: La gestación de la prensa moderna en Chile (Santiago: LOM Ediciones-Universidad Arcis, 2001). Ossandón, El Crepúsculo de los sabios y la irrupción de los publicistas. Prensa y espacio público en Chile (siglo XIX) (Santiago: LOM Ediciones: Universidad Arcis, 1998).

${ }^{11}$ Bernardo Subercaseaux, "La Historia del Libro en Chile: Desde la Colonia hasta el Bicentenario", en Entre las Alas y el Plomo, 34.
} 
las leyes laicas de registro civil en la década de 1880 y finalmente con la separación de Iglesia y Estado en $1925^{12}$.

En lo que respecta a la controversia entre la masonería y la Iglesia católica, esta toma nueva vigencia con la campaña antimasónica desarrollado desde el Vaticano por el Papa Pío IX, quien a partir de 1846 con la encíclica "Qui pluribus" comienza su cruzada, la cual se intensifica con la publicación de "Quanta cura" y el "Syllabus" en 1864. La razón aludida por el Pontífice tenía que ver con la supuesta maquinación que hacían las sociedades secretas contra el poder de la Iglesia y los legítimos gobiernos ${ }^{13}$.

La causa contra esta "herejía" llegó a Chile gracias a la visita que realizó el arzobispo de Santiago, Rafael Valentín Valdivieso al Vaticano en 1859 y, en segundo lugar, la traducción de libros antimasónicos franceses al español, los cuales fueron difundidos por la Iglesia local apoyada por el sector conservador.

\section{Valparaíso y la masonería}

A mediados del siglo XIX la ciudad de Valparaíso se fue transformando en el principal puerto del pacifico sur, debido a que concentraba gran parte de la actividad económica de la región. Esto permitió que se fuera constituyendo un espacio excepcional para la modernización de Chile a la vez que fue conformando un laboratorio de nuevas prácticas asociativas debido a la cantidad importante de inmigrantes que albergaba. Las comunidades de europeos y norteamericanos que se establecieron se convirtieron en un grupo de poder y agentes de modernización, no solo en materia económica, ya que encabezaban las actividades mercantiles del puerto, sino que también tuvieron un importante rol en la innovación de la sociabilidad haciendo de Valparaíso una ciudad cosmopolita que contrastaba con la tradición. Era una ciudad donde se manifestaba abiertamente la primacía del progreso, fundamentalmente de raíz protestante, por sobre la tradición religiosa ${ }^{14}$.

Las primeras logias en Chile precisamente se establecieron en la ciudad de Valparaíso de la mano de los inmigrantes europeos radicados en el puerto, pero prontamente se fueron interiorizando con la vida nacional e incorporando a un mayor número de chilenos ${ }^{15}$.

\footnotetext{
${ }^{12}$ Serrano. "La escuela chilena y la definición de lo público", 340-362. El tema es extensamente tratado en Serrano, ¿Qué hacer con Dios en la República? Política y secularización en Chile (1845-1885) (Santiago: FCE, 2008).

${ }^{13}$ José Antonio Ferrer Benimeli, El Contubernio Judeo-Masónico-Comunista. Del satanismo al escándalo de la P-2 (Madrid: Ediciones Istmo, 1982).

${ }^{14}$ Felipe Santiago del Solar, Las Logias de Ultramar (Santiago: Editorial Occidente, 2012), 61-68. A propósito también ver. René Millar, “Aspectos de la religiosidad porteña: Valparaíso 1830-1930”, Historia 33 (2000): 297-368.

${ }^{15}$ Para ver en detalle la conformación de las primeras logias en Valparaíso: Del Solar, Las Logias de Ultramar, 61- 115 .
} 
La logia L'Etoile du Pacifique, que trabajaba en francés y Bethasa que lo hacía en inglés, fueron los primeros talleres en funcionamiento, sin embargo, pronto se comprendió que, si la masonería no era cultivada y propagada por los chilenos que aplicaran las enseñanzas en su propia sociedad, la Orden no progresaría en el país. Por tanto, se comenzó a iniciar a intelectuales porteños de la mano del comerciante masón Manuel de Lima, quien planteó a las autoridades de la logia francesa la necesidad de fundar una logia de habla hispana, la cual se erigió bajo el nombre de Unión Fraternal, y comenzó a funcionar en Valparaíso en julio de $1853^{16}$ bajo los auspicios del Gran Oriente de Francia. En el grupo fundador, no había chilenos y en sus primeros años su presencia fue escaza. Sin embargo, al promediar 1854, la logia albergó a destacados miembros de la elite como José Victorino Lastarria, Jacinto Chacón, Juan de Dios Arlegui y Blas Cuevas. Además, se incorporaron importantes exiliados argentinos, como Domingo Faustino Sarmiento, Javier Villanueva, Mariano E. de Sarratea, Jacinto Rodríguez Peña y José Manuel Moreno ${ }^{17}$. En uno de los discursos inaugurales de la fundación de la logia, José Victorino Lastarria dejó de manifiesto la concepción de masonería que se estaba impulsando, la cual era pensada como una escuela republicana para la moral y las virtudes:

Vosotros mismos tenéis pruebas evidentes de que el espíritu masónico y las virtudes que distinguen a este Taller no son ilusorios. Jamás la viuda, el huérfano y el hermano en desgracia han golpeado a nuestras puertas sin ser consolados, y los profanos ciegos que, por su mérito, han podido penetrar en este santuario, han encontrado pronto la ciencia y la luz que buscaban. Nosotros nos esforzamos por esparcir lo más posible esta luz, porque sabemos que sin ella no podemos asegurar el triunfo de la verdad, de la justicia y de la libertad! El mundo entero, y nuestra América sobretodo, tienen necesidad de esta luz para disipar las tinieblas de la ignorancia (...) de la mentira y de las usurpaciones de la ambición.

La masonería es una institución social que, por su propia esencia, tiene la misión de propagar la moral; y es necesario, entonces, que llegue a poseer la organización y el vigor de todas las otras instituciones sociales dedicadas a la realización de otras ideas fundamentales.

La Justicia está representada por el Estado, la religión por la Iglesia, la ciencia por la Universidad. Es, entonces, indispensable que la moral, idea fundamental también del género humano, tenga, como las otras ideas, su representante que se encargue de realizarla y de liberarla de la dependencia en que vive; y sólo la Orden Masónica puede llegar a ser ese representante. Y que no se nos venga a reprochar que los misterios y las fórmulas que

\footnotetext{
16 "Informe del Inspector General de la Logia Masónica de Valparaíso al Gran Oriente de Francia, de 30 de julio de 1854" en Günter Böhm, "Manuel de Lima, fundador de la Masonería chilena", Revista Judaica iberoamericana 3 (1979): 61-64.

${ }^{17}$ Juan Ricardo Couyoumdjian, "Masonería de habla inglesa en Chile: algunas noticias", Boletín de la Academia Chilena de la Historia XLII, no. 105 (1995): 188.
} 
empleamos se oponen a la realización de esta idea, porque son esos misterios y esas fórmulas las que dan a nuestra institución el carácter sano que la vuelve respetable y la preserva de los peligros de la vulgaridad ${ }^{18}$.

Según Benjamín Oviedo, Valparaíso no solo fue la cuna de la masonería chilena, sino que habría sido un verdadero foco masónico, donde se desarrolló y creció la tendencia que dio lugar a los primeros Talleres y dilató su influencia a las ciudades de mayor importancia de la República ${ }^{19}$. De hecho, para 1855, las tres logias constituidas en Valparaíso, en conjunto contaban con alrededor de 150 miembros activos ${ }^{20}$.

Dentro de los principales objetivos de la masonería de la época, estaba la construcción de una comunidad de filántropos que irrumpiera en el espacio público con obras que fueran en ayuda de la población más desfavorecida.

Para la orden, al igual que para la gran parte de la intelectualidad chilena, la educación era el principal instrumento del progreso, tanto individual como colectivo. Por ello en octubre de 1868 se fundó en la ciudad de Valparaíso una filial de la Sociedad de Instrucción Primaria de Santiago y como parte de su directorio se encontraban los masones Juan de Dios Arlegui, Benicio Álamos y Blas Cuevas Zamora, quienes se comprometieron a fundar una Sociedad destinada exclusivamente a fomentar la educación en la ciudad, específicamente la enseñanza básica en los sectores populares que no tenían acceso a la misma $^{21}$.

Fue precisamente en el marco de estas iniciativas que la masonería irrumpió en el espacio público con la fundación de la primera escuela laica.

\section{La escuela "atea"}

La Escuela Blas Cuevas fue inaugurada el 25 de febrero de 1872 y llevó el nombre de uno de los masones y filántropos más ilustres de la ciudad ${ }^{22}$. Inició sus actividades con 140 alumnos matriculados y debido a su éxito al poco tiempo habilitó una sección de niñas

\footnotetext{
${ }^{18}$ Traducción de Manuel Romo Archivo Masónico no. 1, 12. Citado en Del Solar, Las Logias de Ultramar, 98.

${ }_{19}$ Benjamín Oviedo, La Masonería en Chile. Bosquejo Histórico: La Colonia, La Independencia, La República. Primera parte hasta 1900 (Santiago: Impr. y Lit. Universo, 1929), 185.

${ }^{20}$ Böhm, "Manuel de Lima, fundador de la Masonería chilena", 75.

${ }^{21}$ Manuel Sepúlveda, Crónicas de la Masonería Chilena (1750-1944) (Santiago: Ediciones de la Gran Logia de Chile, 1997), Tomo I, 255.

${ }^{22}$ Marcos Parada Ulloa ha trabajado la relación entre masonería y educación en el Chile finisecular abordando la fundación de la Escuela Blas Cuevas en "Principios de sociabilidad en la Escuela Blas Cuevas 1870-1872", Tiempo y espacio 32 (2014):123-139, el autor aborda la historia de la fundación de la Escuela y reproduce someramente parte del debate suscitado a propósito de la irrupción de la masonería en la educación, para ello considera relevante la sociabilidad desplegada en las logias masónicas en tanto estas habrían actuado como centros de opinión llevando un proyecto valórico a los sectores subalternos. Otros trabajos del autor respecto a la relación entre educación y masonería: "La escuela primaria: un proyecto civilizador, libertario y laico 1860-1872", Tiempo y espacio 26 (2011): 95-119; y Educación y sociabilidad: La presencia de la masonería en Chile (Editorial Académica Española, 2016).
} 
y otra de adultos ${ }^{23}$. El directorio estaba compuesto por los masones Ramón Allende Padín como presidente; Carlos Renard como vicepresidente; Diego Feliú como tesorero y David Trumbull, E. Münchmeyer y Antonio Flusser como directores del establecimiento. En general reglamento interno de la escuela no se diferenciaba mayormente del adoptado por las escuelas públicas.

En su acto de inauguración, Ramón Allende Padín, afirmaba que la instrucción que se impartiría en la escuela no contemplaría la enseñanza del catecismo de religión, ello porque consideraban que la educación religiosa no correspondía a la escuela sino al hogar doméstico, ya que los padres serían quienes deberían decidir qué instrucción religiosa se les entregaba a los niños. Allende justificaba esta decisión aludiendo a que:

...un establecimiento mantenido por personas de distintas creencias, no puede, si no es obrando fuera de la razón, imponer una y enseñarla como obligación, siendo también que la escuela, asilo de todos los niños, no debe tener creer oficial como no lo debe tener tampoco el Estado, asilo común de los ciudadanos ${ }^{24}$.

La escuela reemplazaría la enseñanza de la religión católica por lecciones de moral, las cuales permitirían el desarrollo en los alumnos de virtudes y deberes en relación a la familia, la patria, la humanidad y el deber del ciudadano.

Este discurso y la puesta en funcionamiento de la escuela causaron una fuerte discusión en la prensa llegando a alcanzar importancia nacional. La primera reacción a la fundación de la escuela vino de parte de Mariano Casanova, gobernador eclesiástico de Valparaíso, quien publicó una circular al respecto en la cual destacaba la importancia de la instrucción de la juventud, ya que de ello dependería el progreso o decadencia de una sociedad, por tanto, dicha instrucción debía ser excluyentemente católica.

Para Casanova, sin Dios no se podía educar a la juventud y calificaba la escuela como "atea" y desde ahí, como el mayor mal que puede aquejar a los niños católicos. Argumentó que aquella calificación estaba justificada porque la escuela no contemplaba la enseñanza de la religión católica. El perjuicio a la sociedad vendría por el hecho de que sin religión no se podría enseñar moral, pero además aseguraba que la fundación de la escuela respondería al propósito de reclutar posteriormente a los niños en las logias e instruirlos en la masonería práctica ${ }^{25}$.

\footnotetext{
${ }^{23}$ Oviedo, La Masonería en Chile, 266.

${ }^{24}$ Reproducido en: Oviedo, La Masonería en Chile, 266.

${ }^{25}$ Mariano Casanova, "Circular dirigida a los Señores Curas, Administrador de la Matriz del Salvador, de los Doce Apóstoles y del Espíritu Santo. Valparaíso", noviembre 26 de 1872. En La Relijión y la masonería: recopilación de los principales artículos publicados en los diarios, a consecuencia de una circular sobre la escuela atea del Sr. Gobernador Eclesiástico de Valparaíso (Valparaíso: Impr. del Mercurio, 1873), 3-9.
} 
Prontamente el periódico El Mercurio hizo eco del debate y se convirtió en el portavoz de una serie de cartas que iban dirigidas contra la Escuela Blas Cuevas y, por ende, contra la masonería.

Los católicos apoyaban lo expresado por el gobernador Casanova, argumentando sobre el gran perjuicio social que significaba el tipo de educación carente de religión que se impartía en la escuela, sobre todo cuando iba dirigida a los sectores más pobres de la población, ya que sería ese sector social el que más necesitarían el catecismo religioso, debido a que los padres de estos niños, en su condición de pobres, se encontrarían imposibilitados de ofrecer la educación moral y religiosa, elemento fundamental para el orden social ${ }^{26}$.

Para la opinión católica, el catecismo de religión no solo enseñaba principios especulativos, sino que también, difundía las enseñanzas de la ley de Dios. Con el catecismo el niño aprendería que es "malo robar, mentir y obrar en el mal". De esta forma, se argumentaba que todas las ideas morales de la sociedad se extraerían del catecismo católico, "a más de ilustrar la intelijencia y dirijir el corazón, el catecismo relijioso enseña los medios conducentes y eficaces para que el hombre cumpla con sus deberes naturales y sobrenaturales, prometiéndole felicidad temporal y eterna",27. La religión ensañaría a los niños a dirigir y dominar sus malas costumbres e inclinaciones, funcionando como medio de disciplinamiento, lo cual como hemos visto, era la tarea prioritaria de las escuelas primarias.

Fuera de la religión, según los católicos, no habría moral que articule el orden social que la tranquilidad de la nación necesita. La religión sería la que enseñaría al niño a dirigir y dominar sus pasiones y la mala inclinación a partir de premios y castigos eternos, el catecismo entonces, sería considerado la única y verdadera filosofía popular, el código verdadero de deberes.

Insistían en la utilidad civil que tiene la enseñanza de la religión católica, la cual tendría un poder inmenso de civilización. A partir de ella se formarían ciudadanos "que unan a la cultura de la intelijencia, la firmeza de ánimo y la sumisión al deber". Ya que, si solo se instruye el pensamiento, los hombres solo se centrarían en sus intereses formando "una civilización material, egoísta y grosera"28.

La crítica, como podemos ver, estuvo centrada en que en la educación impartida al interior de la Escuela Blas Cuevas no contemplaba el catecismo católico. Pero a partir de allí, se levantaron una serie de ataques desde la prensa hacia las ideas y los proyectos de la masonería. Lo interesante del ataque desde el catolicismo y el sector ultramontano porteño

\footnotetext{
${ }^{26}$ Un Ultramontano, "El señor Casanova y la masonería", El Mercurio, en La Relijión y la masonería, 14-17.

${ }^{27}$ Mariano Casanova, "Carta dirigida a Señor Cura Don. J. Alejo Infante", El Mercurio, 12 diciembre de 1872, en La Relijión y la masonería. 29-33.

28 "Escuelas ateas y protestantes" El Independiente 10 de diciembre de 1872. En La Relijión y La Masonería. 46.
} 
es que, como se verá a continuación, va delimitando y configurando en el espacio público una determinada imagen de la Orden y su rol en la sociedad.

\section{La defensa de la masonería porteña}

La Gran Logia de Chile formó una comisión ${ }^{29}$ para dar respuesta a los ataques y acusaciones que se le hacían desde la prensa y elaboró una respuesta en el periódico $E l$ Mercurio el día 13 de diciembre de 1872 . La misiva comienza con la cita del artículo $1^{\circ}$ y $2^{\circ}$ de la Constitución de la Orden, esto es, que la masonería tiene por base:

la existencia de Dios, la inmortalidad del alma y el amor a la humanidad. La Masonería no se ocupa de las diversas relijiones existentes en el mundo, ni de las constituciones civiles de los estados: a la altura en que se coloca, debe respetar y respeta, tanto la fé relijiosa, como la simpatía política de sus miembros. En consecuencia, en sus reuniones toda discusión que tienda a ese objeto, queda espresa y formalmente prohibida ${ }^{30}$.

Luego de aquella aclaración de principios, pasan a argumentar que no se le puede llamar "atea" a la escuela Blas Cuevas ya que "ateo" se le denomina a aquellos que profesan el ateísmo y no podía "aplicarse ese calificativo a una escuela en que no se habla de religión" 31 . Según La Comisión, la gente pobre pronto comprendió que no tenía nada malo ya que se les ensañaba a sus hijos sin exigir la abjuración de su fe.

Aseguraban que el propósito de su defensa en la esfera pública tenía el objetivo de evitar confusiones y para que no se les atribuyeran artículos extraños, por tanto, afirmaban que era una explicación al público y no una respuesta al señor Casanova, ya que ello sería más bien, entrar en polémicas religiosas lo cual solo serviría para azuzar odios de los que la masonería quería privar al país.

Comenzaron su defensa con una explicación de los fines que persiguen, con el objetivo de argumentar por qué consideraban necesario la educación separada del ámbito religioso. Llamaban a la formación de un campo neutral, en el que todos los hombres honrados y de buena fe y de cualquier religión trabajaran juntos "por la virtud, por la moral, por la caridad y por la ilustración”, lo cual los llevaría a la verdad y la justicia. Llamaron a respetar la conciencia de todos los hombres, "puesto que si hai tantas creencias en el mundo, es justo pensar que con la mejor buena fé y pureza se puede creer en lo que nosotros no creemos". Sostenían que era mejor aconsejar a los hombres para que todos los

\footnotetext{
${ }^{29}$ La comisión estuvo compuesta por Ramón Allende Padin, Benicio Álamos Gonzalez. Eduardo de la Barra e Isidoro Errázuriz.

${ }^{30}$ Artículo $1^{\circ}$ y $2^{\circ}$ de la Constitución de la òrden masónica. En La Comisión, "La Masonería y el Gobernador Eclesiástico", El Mercurio, 13 de diciembre de 1872, en La Relijión y La Masonería, 71.

${ }^{31}$ La Comisión, "La Masonería y el Gobernador Eclesiástico", El Mercurio, 13 de diciembre de 1872, en La Relijión y La Masonería, 72.
} 
días darse cuenta de su Creador, de su existencia, de su origen y de su fin; que estudien los libros de su religión y que se ilustren en todos los grandes problemas que dignifican al hombre ${ }^{32}$.

En vista de que a lo largo de la historia de la humanidad los hombres han intentado imponer su creencia religiosa al resto causando grandes perjuicios, la masonería hacía un llamado:

hagamos lo que dijo Confucio ahora 2300 años y lo que ha dicho Jesús ahora 1872 años: amemos a los otros como a nosotros mismos (...) El amor, la caridad, la buena fe en las intenciones y el respeto mutuo derramaran sobre la humanidad una suave calma. Los hombres se oirán; las grandes cuestiones se oirán por razonamientos, y al fin triunfará el que esté en posesión de la verdad ${ }^{33}$.

Los hombres, según La Comisión, no serían bestias a las que se pueda gobernar con el látigo del fanático, sino que serían seres nobles y generosos que se acercan a quienes los respetan.

Con lo anterior, pretendían argumentar que la masonería no era atea, sino que lo que intentaba era apaciguar los ánimos de las diferentes religiones para establecer la paz y acercarse a Dios. Por ello, afirmaban, que si vivían en el misterio no era por temor a la luz, sino por alejarse de las pasiones políticas, religiosas y sociales. Si no predicaban una religión determinada, hacían un llamado a que todos los masones se instruyeran en los evangelios de su religión, a diferencia de los sacerdotes de algunas creencias que impedían que sus miembros se instruyeran en sus dogmas. "Si protegemos a nuestros hermanos masones (afirmaba La Comisión) no por eso perseguimos a los profanos. Si no por el contrario, les damos escuelas y casas de beneficencia, sin exigirles que abjuren de su fe, que crean forzosamente en nuestras creencias y que se sometan servilmente a nuestra dirección"34.

En otro artículo publicado por el mismo periódico, sostienen que la Escuela Blas Cuevas se fundó siguiendo el propósito de constituirse en un campo neutral en búsqueda del mayor beneficio social y la ilustración, "recogiendo suscripciones entre neo-católicos, antiguos católicos, protestantes, racionalistas, judíos, etc" $" 35$. Por tanto, era necesario que no se enseñara religión en la escuela, ya que no era posible enseñarlas todas, ni era justo obligar a las personas de distintas creencias a costear la enseñanza católica. Junto a ello, examinando la panorámica del periodo, afirmaban que las distintas religiones fundaban sus escuelas justificando sus creencias por sobre las demás y atacaban sistemáticamente a las

\footnotetext{
${ }^{32}$ La Comisión, "La Masonería y el Gobernador Eclesiástico”, 72.

${ }^{33}$ La Comisión, "La Masonería y el Gobernador Eclesiástico", 72.

${ }^{34}$ La Comisión, "La Masonería y el Gobernador Eclesiástico", 73.

${ }^{35}$ La Comisión, "La Escuela Blas Cuevas y el Gobernador Eclesiástico", El Mercurio, 14 diciembre de 1872, en La Relijión y La Masonería, 74.
} 
otras religiones, además que quienes no pertenecían a esas creencias no fundaban escuelas, ya sea por falta de recursos o porque los hombres que sí los tenían se negaban a costear las escuelas católicas. De esto modo, suprimiendo el aprendizaje de la religión, se podría instruir al pueblo y enseñarle conocimientos generales que les sirvan para ganarse la vida.

Sostenían igualmente, que dejar la religión fuera de los colegios permitirá a los sectores más vulnerables concentrarse en aquellos conocimientos que les fueran de mayor utilidad para su vida:

(...) la ilustración de la república perdía muchas de las erogaciones de los hombres jenerosos. Pero por el contrario, suprimiendo el aprendizaje de una relijion, se podrían utilizar esos elementos en enseñar al pueblo la lectura, la escritura, la aritmética, la gramática castellana y los otros conocimientos jenerales que pudieran servirle para ganarse la vida y para preparase a adquirir mayor instrucción ${ }^{36}$.

Aseguraban que, si en la escuela no se hablaba de religión, no se les aconsejaba a los niños que no creyeran en Dios, si no que por el contrario, se les enseñaba a conocerle y adorarle, por lo que el calificativo de "atea" no les haría justicia y respondería más bien a un ataque para espantar a los creyentes y a los pobres. Sin embargo, afirmaban que lo único que querían hacer eran obras de caridad sin negociar las granjerías de poder, honores ni riquezas, "sin sacar siquiera honores para nuestra institución, puesto que si nuestros enemigos no hubieran publicado que la escuela Blas Cuevas era nuestra obra, nadie lo habría sabido". Para la masonería, entonces, una de las funciones principales de la educación se centraba en alejar al pueblo de la ignorancia para que se lograra el progreso, por tanto, levantar calumnias contra la escuela iba en contra del desarrollo del país, argumento que entre en directa sintonía con el discurso liberal ${ }^{37}$.

Siendo así, en la medida que respetan todas las religiones, no pueden enseñar a los niños doctrinas de odio que dividan a los hombres y precisamente eso era lo que contendrían algunos artículos del catecismo católico. "Partidarios de la tolerancia y enemigos de inútiles y odiosas discusiones, apartamos de manos de los niños todo libro que pueda despertar en él precoces instintos y hacerle perder la vida y el respeto a sus semejantes" 38 .

Entre las doctrinas que enseñaba el catecismo y que La Comisión no aceptaba, estaba el desprestigio que realizaban del protestantismo, justificándose en las acciones de Lutero como su matrimonio y otros actos como el uso de palabras obscenas o injuriosas. Ello, según la masonería, nada tendría que ver con los dogmas, además, no podrían permitir que se inculcara en la conciencia de los niños ideas tan estrechas y mezquinas sobre los

\footnotetext{
${ }^{36}$ La Comisión, "La Escuela Blas Cuevas y el Gobernador Eclesiástico", 74.

${ }^{37}$ La Comisión, "La Escuela Blas Cuevas y el Gobernador Eclesiástico", 76.

${ }^{38}$ La Comisión, "La Moral y el Catecismo", El Mercurio, 17 de diciembre de 1872, en La Relijión y La Masonería, 81.
} 
grandes acontecimientos de la humanidad, "reduciendo la moral y la relijion a chicanas de baja polémica" 39 .

Tampoco podían tolerar que se afirmara que fuera de la Iglesia católica no había salvación, aunque no quisieron discutir la verdad o falsedad de aquella creencia, más bien, replicaron que quienes la creían, podían enseñarla en las escuelas financiadas con sus propios fondos, pero ellos que recibían erogaciones de personas provenientes de diversos credos, "para enseñar a los hijos del pueblo, ¿podíamos decirles que reputasen a sus mismos benefactores como réprobos en vida y en muerte?"40.

Concluyen afirmando que respetan la moral del evangelio y que siempre enseñan a los niños a adorar y amar a Dios, a cumplir los deberes religiosos y a amar al prójimo y beneficiarlo con obras de misericordia

\section{La arremetida católica}

El sector católico no tardó en responder a los argumentos emitidos por la Gran Logia de Chile. Iniciaron un nuevo debate definiendo, según su punto de vista, lo que sería la masonería. Al respecto, afirmaron que era anti-religiosa, ya que negaba toda religión. En segundo lugar, sostuvieron que era "antisocial ya que, proclamando la moral independiente de todo dogma, proclama el ateísmo político. En tercer lugar, sería anti democrática, "porque por su régimen de gobierno es una oligarquía y porque su espíritu de gobierno es autocrático y antirrepublicano". En síntesis, afirman que sería imposible ser masón y al mismo tiempo ser católico" 41 .

Entre el 20 y 26 de diciembre de 1872 el Mercurio publicó una descripción panorámica de la masonería firmada por alguien que se hacía llamar "un católico". Citando a Courcelle de Sencuil sostenía que la masonería era "el preliminar de una conspiración que trata de fomentar y propagar el odio contra el poder establecido y de preparar su ruina por medio de insurrecciones". Sería, para ellos, algo así como un árbol funesto que crece y se desarrolla en las tinieblas ${ }^{42}$.

Con respecto a lo expuesto en los escritos de La Comisión, la opinión católica concluye que a partir de esto se desprendía que la masonería, a pesar de la aparente moderación con la que había redactado sus escritos, tendría un odio encarnizado hacia la Iglesia católica. El escrito estaría saturado de blasfemias, impiedades y calumnias contra la religión ${ }^{43}$, además de ser una prueba de su carácter anti-religioso. ${ }^{44}$

\footnotetext{
${ }^{39}$ La Comisión, "La Moral y el Catecismo", 82.

${ }^{40}$ La Comisión, "La Moral y el Catecismo", 83-85.

${ }^{41}$ Un católico, "La Masonería en Campaña”, El Independiente, 24 de diciembre de 1872, en La Relijión y La Masonería., 96.

${ }^{42}$ Un católico, El Mercurio, 20 al 26 de diciembre de 1872, en La Relijión y La Masonería, 101.

${ }^{43}$ Un católico, El Mercurio, 20 al 26 de diciembre de1872, 102.

${ }^{44}$ Un católico, El Mercurio, 20 al 26 de diciembre de 1872, 103.
} 
Junto a lo anterior, el secreto, que constituye su distintivo más conocido, suministraría el mayor argumento en su contra, al respecto aseguraban "que nadie busca las sombras para cumplir con el deber, para obrar el bien" 45 . Por tanto, seria sospechosa de inmoralidad por el hecho mismo de ser secreta y porque exigirían a sus miembros promesas y les impondrían compromisos que solo se podrían cumplir olvidando la responsabilidad ante Dios ${ }^{46}$.

Finalmente, apuntan que la masonería sería un obstáculo a la democracia y a la república, precisamente por el secreto, ya que la publicidad sería una característica imprescindible ambas.

Si la democracia busca la luz como las mariposas, la masonería busca la oscuridad como los búhos y los murciélagos (...) y en este siglo en que la prensa y, por la prensa, el pueblo, penetra todos los arcanos y rasga los velos aún más cuidadosamente guardados, en este siglo cuando la publicidad no solo invade todo sino que también es solicitada y estimada por todos, la masonería la evita, la teme y hace esfuerzos tenaces para sustraerse a esa lei universal, que es la primera lei de los países libres y de los hombres que sinceramente aman la libertad ${ }^{47}$.

Así mismo el carácter jerárquico de la masonería iría en contra también de los principios democráticos y republicanos, ya que no podría haber un país de iniciados y profanos, ni de aprendices y maestros. En una república, se afirmaba, solo debe haber ciudadanos iguales en derechos ${ }^{48}$.

Pero las críticas no pararon aquí, sino que se sucedieron en una seguidilla de publicaciones protagonizadas por miembros de la iglesia y de la opinión católica. Cabe destacar, que en su mayoría estuvieron destinadas a desprestigiar a la Orden en la esfera pública, poniendo en evidencia sus objetivos y los resultados funestos que estos tendrían para la sociedad ${ }^{49}$.

\section{Conclusión}

La revisión de esta polémica, que a su vez forma parte del debate entre liberalismo e Iglesia, nos permite vislumbrar un aspecto de la configuración que va realizando la masonería en el espacio público. A partir de los ataques provenientes del sector

\footnotetext{
${ }^{45}$ El Independiente, 27 de diciembre de 1872, en La Relijión y La Masonería, 125.

${ }^{46}$ El Independiente, 27 de diciembre de 1872, 127.

${ }^{47}$ XVII La Francmasonería, III, La Francmasonería y la democracia, El Independiente, 29 de diciembre de 1872, en La Relijión y La Masonería, 131.

${ }^{48}$ I XVII La Francmasonería, III, La Francmasonería y la democracia, El Independiente, 29 de diciembre de $1872,133$.

${ }^{49}$ Ver El Independiente del 5 y el 12 de enero de 1873.
} 
conservador y de la Iglesia católica, la Gran Logia de Chile presenta sus principios, creencias y su rol en la sociedad, en el marco de su defensa de la Escuela Blas Cuevas. En voz de los católicos "era la primera vez que en Chile la masonería saliendo de la oscuridad y de las tinieblas en que habita y quitándose la máscara con que se cubre, se presenta al público y con el mayor cinismo da a conocer los principios antirreligiosos, antisociales y anti-políticos que son la base y fundamentos de sus logias"

De lo presentado podemos extraer que la masonería fue investida de valores racionalistas, naturalistas y ateos que constituían de acuerdo a la visión de los conservadores, las características específicas del liberalismo, en un periodo en el que en Chile se estaba discutiendo acerca de las características que debía tener el Estado moderno.

El conflicto entre liberalismo y catolicismo se planteó como una lucha de ideales a partir de los que se debía regir la sociedad de donde deriva el conflicto acerca del rol que debía tener la iglesia en educación.

La principal estrategia desde la Iglesia católica fue otorgarle a la masonería un carácter anticlerical o "ateo", ello debe entenderse dentro del contexto de un país con una población mayoritariamente católica y con un Estado que la proclama como religión oficial. La masonería en respuesta, se apropió del discurso secular decimonónico contra la Iglesia caracterizándola con epítetos de "fanatismo", "superstición" e "ignorancia" en nombre de la "razón”, el "progreso" y la "civilización”. Este enfrentamiento hizo que la masonería se alineara de forma natural con el liberalismo político de la época y fuera presentando a la sociedad a partir del debate en la esfera pública una imagen de sí misma y de su proyecto social que terminarían otorgándole una impronta que hasta el día de hoy reivindican como suya.

\section{Fuentes}

La Relijión y la masonería: recopilación de los principales artículos publicados en los diarios, a consecuencia de una circular sobre la escuela atea del Sr. Gobernador Eclesiástico de Valparaíso. Valparaíso: Impr. del Mercurio, 1873.

\section{Bibliografía}

Böhm, Günter. "Manuel de Lima, fundador de la Masonería chilena". Revista Judaica iberoamericana 3 (1979): 61-64.

Collier, Simon. Chile: la construcción de una república 1830-1865: política e ideas. Santiago: Ediciones Universidad Católica de Chile, 2005.

\footnotetext{
${ }^{50}$ Un católico, "La Masonería en Campaña”, El Independiente, 24 de diciembre de 1872, en La Relijión y La Masonería, 95.
} 
Couyoumdjian, Juan Ricardo. "Masonería de habla inglesa en Chile: algunas noticias". Boletín de la Academia Chilena de la Historia XLII, no. 105 (1995): 185-208.

Del Solar, Felipe Santiago. Las Logias de Ultramar. Santiago: Editorial Occidente, 2012.

Ferrer Benimeli, José Antonio. El Contubernio Judeo-Masónico-Comunista. Del satanismo al escándalo de la P-2. Madrid: Ediciones Istmo, 1982.

Gazmuri, Cristian. El " 48 " chileno: igualitarios, reformistas radicales, masones y bomberos. Santiago: Universitaria, 1999.

Jocelyn-Holt, Alfredo. "Liberalismo y Modernidad. Ideología y Simbolismo en el Chile Decimonónico: Un Marco Teórico”. En La Revolución Francesa y Chile. Editado por Ricardo Krebs y Cristián Gazmuri. Santiago: Ed. Universitaria, 1990.

Millar, René. “Aspectos de la religiosidad porteña: Valparaíso 1830-1930”. Historia 33 (2000): 297-368.

Ossandón, Carlos. El Crepúsculo de los sabios y la irrupción de los publicistas. Prensa y espacio público en Chile (siglo XIX). Santiago: LOM Ediciones-Universidad Arcis, 1998.

Ossandón, Carlos y Eduardo Santa Cruz. Entre las Alas y el Plomo: La gestación de la prensa moderna en Chile. Santiago: LOM ediciones-Universidad ARCIS, 2001.

Oviedo, Benjamín. La Masonería en Chile. Bosquejo Histórico: La Colonia, La Independencia, La República. Primera parte hasta 1900. Santiago: Impr. y Lit. Universo, 1929.

Parada Ulloa, Marcos. "La escuela primaria: un proyecto civilizador, libertario y laico 1860-1872. Tiempo y espacio 26 (2011): 95-119.

Parada Ulloa, Marcos. "Principios de sociabilidad en la Escuela Blas Cuevas 1870-1872". Tiempo y espacio 32 (2014): 123-139.

Parada Ulloa, Marcos. Educación y sociabilidad: La presencia de la masonería en Chile. Editorial Académica Española, 2016.

Pinto, Jorge. "Proyectos de la elite chilena del siglo XIX". ALPHA 27 (2008): 123-145.

Romero, José Luis. Latinoamérica. Las ciudades y las ideas. Buenos Aires: Siglo XXI, 2001

Sepúlveda, Manuel. Crónicas de la Masonería Chilena (1750-1944). Santiago: Ediciones de la Gran Logia de Chile, 1997.

Sabato, Hilda. "La esfera pública en Iberoamérica. Reflexiones sobre los usos de una categoría". En Sociedad civil en América Latina: representación de intereses y gobernabilidad. Editado por Peter Hengstenberg, Karl Kohut y Gunther Maihold. Caracas: Friedrich Ebert Stiftung/Nueva Sociedad, 1999.

Serrano, Sol. Universidad y Nación. Chile en el siglo XIX. Santiago: Universitaria, 1994.

Serrano, Sol. "La escuela chilena y la definición de lo público". En Los espacios públicos en Iberoamérica. Ambigüedades y problemas. Siglos XVIII-XIX. Editado por 
François-Xavier Guerra y Annick Lempérière. Ciudad de México: Fondo de Cultura Económica, 1998.

Serrano, Sol. ¿Qué hacer con Dios en la República? Política y secularización en Chile (1845-1885). Santiago: FCE, 2008.

Serrano, Sol, Macarena Ponce de León y Francisca Rengifo. Historia de la Educación en Chile (1810-2010). Tomo I. Aprender a leer y escribir (1810-1880). Santiago: Editorial Taurus, 2013.

Stuven, Ana María. La Seducción de un orden: las élites y la construcción de Chile en las polémicas culturales y políticas del siglo XIX. Santiago: Ediciones Universidad Católica de Chile, 2000.

Subercaseaux, Bernardo. La Historia del Libro en Chile: Desde la Colonia hasta el Bicentenario. Santiago: LOM Ediciones, 2010. 